\title{
Vitamin E succinate exerts anti-tumour effects on human cervical cancer cells via the CD47-SIRPa pathway both in vivo and in vitro
}

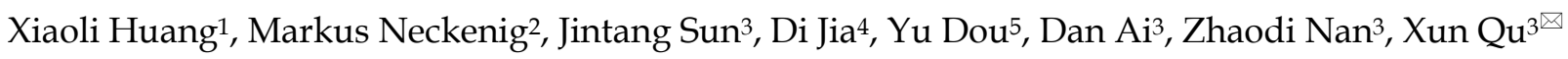 \\ 1. Department of Nutrition, Qilu Hospital of Shandong University, School of Medicine, Cheeloo College of Medicine, Shandong University, Jinan, Shandong, \\ China. \\ 2. School of Pharmaceutical Sciences, Shandong University, Jinan, Shandong, China. \\ 3. Institute of Basic Medical Sciences, Qilu Hospital of Shandong University, School of Medicine, Cheeloo College of Medicine, Shandong University, Jinan, \\ Shandong, China. \\ 4. Department of Biochemistry, Qiqihar Medical University, Qiqihar, Heilongiiang, China. \\ 5. Department of Tissue Engineering and Regeneration, School and Hospital of Stomatology, Shandong University \& Shandong Key Laboratory of Oral Tissue \\ Regeneration \& Shandong Engineering Laboratory for Dental Materials and Oral Tissue Regeneration, Jinan, Shandong, China.
}

$\triangle$ Corresponding author: Xun Qu, Institute of Basic Medical Sciences, Qilu Hospital of Shandong University, 107 West Wenhua Road, Jinan, 250012, Shandong, People's Republic of China. Tel.: +86 5318216 9251; fax: +86 5318216 9251; E-mail: quxun@sdu.edu.cn.

(c) The author(s). This is an open access article distributed under the terms of the Creative Commons Attribution License (https://creativecommons.org/licenses/by/4.0/). See http://ivyspring.com/terms for full terms and conditions.

Received: 2020.08.23; Accepted: 2021.04.22; Published: 2021.05.05

\begin{abstract}
Vitamin E succinate (RRR-a-tocopheryl succinate, VES) acts as a potent agent for cancer therapy and has no toxic and side effects on normal tissue cells. However, the mechanism by which VES mediates the effects are not yet fully understood. Here, we hypothesised that VES mediates antitumour activity on human cervical cancer cells via the CD47-SIRPa pathway in vivo and in vitro. Results indicated that the human cervical cancer HeLa cells treated with VES were more efficiently engulfed by THP-1-derived macrophages. In response to VES, the protein expression of CD47 on cell membranes and the mRNA level of CD47 in different human cervical cancer cells significantly decreased. And the level of calreticulin (CRT) mRNA in the VES-treated cells increased. By contrast, CRT protein expression was not altered. miRNA-155, miRNA-133 and miRNA-326 were up-regulated in the VES-treated HeLa cells. Knocking down miRNA-155 and miRNA-133 by RNA interference increased CD47 protein expression in the VES-treated cells. In vivo efficacy was determined in BALB/C nude mice with HeLa xenografts. Results showed that VES reduced tumour growth, increased overall survival and inhibited CD47 in the tumour transcriptionally and translationally. Furthermore, inflammatory factors (TNF- $\alpha$, IL-12, IFN-y, IL-2 and IL-10) in the spleen were altered because of VES treatment. Our results suggest that VES-induced antitumour activity is coupled to the CD47-SIRPa pathway in human cervical HeLa cancer cells.
\end{abstract}

Key words: CD47; vitamin E succinate; cervical cancer cells; vivo; vitro

\section{Introduction}

Cervical cancer is a common malignant tumour from which a good many women are likely to suffer at some stage in their lives with the fourth highest probability by comparison with the incidence rate of other tumours occurrent in women and the seventh most common cancer in the general population [1]. Similarly to other years, in 2018, to give but one example, the global incidence of cervical cancer was as worryingly high as 569,000 cases with a mortality rate of 311,000 cases [2]. Therefore, novel more effective treatment methods are urgently needed to improve the survival rate of patients with cervical cancer. Great advances in the treatment of various human tumours have been achieved through the development of therapies that aim at modulating the immune system [3]. Immunotherapy aims to eliminate cancer cells not only via the adaptive immunity mediated by $\mathrm{T}$ cells but also by utilising innate immune cells, such as macrophages [4]. Macrophages serve both as phagocytes and as 
antigen-presenting cells. Macrophages can act as effectors killing tumour cells either by physical engulfment or by cytotoxin release [5]. The transmembrane protein CD47 has been found to be more highly expressed in a large number of malignant cells. Research has shown that the CD47/the signal regulatory protein alpha (SIRPa) pathway plays an important role in inhibiting the phagocytosis of target cells [6].

CD47 performs a range of important physiological functions, such as adaptive immunity, bone remodelling, cell adhesion, motility, proliferation and survival $[7,8]$. As to its role in tumour development, CD47, which is an ubiquitously expressed surface receptor in all types of cancers, acts as an antiphagocytic "don't eat me" signal, binding to SIRPa on the macrophages and dendritic cells [9]. High expression of CD47 is associated with poor survival in many cancers. Therefore, blockage of the CD47/SIRPa axis is a successful strategy to target and limit cancer cells [10].

A number of previous studies by other groups had already established that Vitamin E succinate (RRR-a-tocopheryl succinate, VES), a derivative of natural vitamin $\mathrm{E}$, has the capacity to inhibit the growth of various cancer cell types in vitro and in vivo $[11,12]$. Our own previous studies had revealed that VES triggers apoptosis and inhibits cell proliferation via several pathways in human gastric cancer cells [13-15]. We also found that VES upregulates the TRAIL expression in human CD4+T cells. Importantly, our previous work had shown that the combination of human CD4+T cells and VES can induce a higher anti-cancer effect against human gastric cancer cells [16], implying that VES possibly suppresses the growth of malignant cells via the immune system. Therefore, we decided to examine the expression of CD47 specifically on the surface of cervical cancer cells. In the present study, our specific focus has been to investigate whether the CD47/SIRPa axis is involved in the VES-induced anti-tumour effect. And we are pleased to report our important finding that, through participation in cell-molecular pathways, VES does indeed have the capacity to decrease CD47 expression of human cervical cancer cells in vitro and in vivo. Moreover, we have found that exposure to VES greatly increases THP-1 macrophage-mediated phagocytosis of these tumour cells, thereby further elucidating the anticancer immune mechanism of VES. To the best of our knowledge, this study is the first one of its kind in that we have specifically investigated the role of the CD47/SIRPa axis in the VES-induced anti-tumour effect.

\section{Materials and Methods}

\section{Cell culture}

Human cervical cancer HeLa and CaSki cells and the promonocytic cell line THP-1 were maintained in RPMI 1640 medium, while human cervical cancer $\mathrm{SiHa}$ cells were maintained in $\alpha$-MEM medium, which were supplemented with $10 \%$ foetal bovine serum and $1 \%$ penicillin-streptomycin double antibody with $5 \% \mathrm{CO}_{2}$ at $37{ }^{\circ} \mathrm{C}$. The cells were sub-cultured at $80 \%$ fusion degree with a proportion of 1:3. Three times, a known quantity of exponentially growing cancer cells were treated with a liquid sample of VES (Sigma, USA) solution of defined concentration for the indicated time periods. The three VES samples had concentrations of 5, 7.5 and 10 $\mathrm{mg} / \mathrm{mL}$ VES respectively - each time dissolved in $0.1 \%$ ethanol as solvent. HeLa and THP-1 cells were obtained from the cell bank of the Chinese Academy of Sciences in Shanghai and the American Type Culture Collection, respectively. CaSki and SiHa cells were respectively obtained from Procell Life Science \& Technology Co. Ltd, and Cancer Center Laboratory of Shandong University.

\section{Phagocytosis assay}

For each well, $2 \times 10^{5}$ THP-1 cells were differentiated with $100 \mathrm{ng} / \mathrm{mL}$ PMA for $48 \mathrm{~h}$. Cells treated with $10 \mu \mathrm{g} / \mathrm{mL}$ VES for $24 \mathrm{~h}$ were fluorescently stained with $5 \mu \mathrm{mol} / \mathrm{L} 5-$ or $6-(\mathrm{N}-$ succinimidyloxycarbonyl)-fluorescein 3',6'-diacetate (CFSE) for $15 \mathrm{~min}$. After treatment, THP-1 macrophages were incubated in serum-free medium for $2 \mathrm{~h}$ before adding $2 \times 10^{5}$ CFSE-labelled HeLa cancer cells. The macrophages were repeatedly washed and subsequently imaged using an inverted microscope. Also, HeLa cell/THP-1 macrophage co-cultures were analysed by flow cytometry after the treatment with PE-conjugated anti-CD11c antibody.

\section{Quantitative real-time PCR assays}

Total RNA was extracted from cells and tissues with TRIzol reagent (Beyotime, China) according to the manufacturer's protocol. cDNA was synthesised with the PrimeScript RT reagent kit (Western Biotechnology). Real-time quantitative PCR (qRT-PCR) analyses were performed with the SYBR Green I and Real-time PCR reagents (Western Biotechnology). The $25 \mu \mathrm{L}$ reaction mixture included $0.5 \mu \mathrm{L}$ of $20 \times$ SYBR Green I buffer, $2 \mu \mathrm{L}$ of the template, $1 \mu \mathrm{L}$ of upstream and downstream specific primers, and $20.5 \mu \mathrm{L}$ of deionised water. RT-PCR included initial denaturing for $4 \mathrm{~min}$ at $94^{\circ} \mathrm{C}, 35$ cycles at $94^{\circ} \mathrm{C}$ for $20 \mathrm{~s}, 60^{\circ} \mathrm{C}$ for $30 \mathrm{~s}$, and $72{ }^{\circ} \mathrm{C}$ for $30 \mathrm{~s}$. Primer sequences were as follows: $\beta$-actin 
(forward: GAGACCTTCAACACCCCAGC; reverse: ATGTCACGCACGATTTCCC), CD47 (forward: TGA AGTGGAAGTTGAACAAATCG; reverse: GCTTAT CCATTTTCAAAGAGGC), calreticulin (CRT) (forward: CTCTGTCGGCCAGTTTCGAG; reverse: TGTATTCTGAGTCTCCGTGCAT), TNF-a (forward: CCCTCCAGAAAAGACACCATG; reverse: CACCC CGAAGTTCAGTAGACAG), IL-12 (forward: CAGCACTTCAGAATCACAACCA; reverse: TCATT TTCACTCTGTAAGGGTCTG), IFN- $\gamma$ (forward: TCAACAACCCACAGGTCCAG; reverse: CGACTC CTTTTCCGCTTCC), IL-2 (forward: AGATGAACTT GGACCTCTGCG; reverse: CATCTCCTCAGAAAGT CCACCAC) and IL-10 (forward: GGACAACAT ACTGCTAACCGACTC; reverse: CCTGGGGCAT CACTTCTACC). The relative quantitative value for each gene was determined to be $2-\Delta \Delta C T$.

\section{Antibodies and flow cytometry analysis}

Anti-CD47 mAb B6H12 and anti-CRT mAb were obtained from Abcam (USA). After treating human cervical cancer cells with VES, they were labelled with a mixture of fluorochrome-conjugated monoclonal antiCD47 antibody and antiCRT antibody of saturating concentration according to the manufacturer's protocol. FACS Calibur (BD Biosciences, San Jose, CA, USA) analysis was used.

\section{Western blotting}

Equal amounts of protein were separated on $10 \%$ SDS-PAGE and transferred onto a nitrocellulose membrane. Immunoblotting was performed using CD47 and $\beta$-actin antibodies (Abcam, USA). The secondary antibodies used were Sheep anti-rabbit IgG (Sigma, USA). After washing with TBST, membranes were incubated with the secondary sheep anti-rabbit IgG (Sigma, USA) and detected with the Western Blue Stabilised Substrate.

\section{Transient transfections}

HeLa cells were plated in 6-well culture plates at a density of $2 \times 10^{5}$ and transfected with siRNA using Lipofectamine 2000 (Invitrogen) according to the manufacturer's protocol. The key steps in summary, for each well, $5 \mu \mathrm{l}$ lipofectamine 2000 was diluted in $245 \mu$ l serum-free Opti-MEM ${ }^{\circledR}-1$ medium (Gibco). This first mixture was carefully added to a solution containing $5 \mu \mathrm{l}$ siRNA in $250 \mu \mathrm{l}$ dilution medium. This resultant mixture solution was incubated for $20 \mathrm{~min}$ at room temperature and then gently dripped into the HeLa cells in antibiotic-free medium; $30 \mathrm{~h}$ after transfections, the cells were treated with VES for $24 \mathrm{~h}$. The inhibitors were designed as follows: miRNA-155 inhibitor (5'-ACCCCUAUCACGAUUAGCAUUAA3'), miRNA-133 inhibitor (5'-CAGCUGGUUGAAG GGGACCAAA-3'), miRNA-326 inhibitor (5'-CUGGA
GGAAGGGCCCAGAGG-3') and miRNA inhibitor NC (5'-CAGUACUUUUGUGUAGUACAA-3').

\section{Xenograft studies of nude mice}

Experiments were approved by the Ethics Committee of Qilu Hospital of Shandong University and conducted according to institutional guidelines for animal care. HeLa cancer cells $\left(1 \times 10^{7}\right.$ cells) were suspended in $200 \mu \mathrm{l}$ phosphate-buffered saline and then injected subcutaneously under the subcutaneous part of the armpit of five-week-old female BALB/C nude mice (Chongqing Tengxin Biotechnology Co., Ltd.). When the size of the xenograft reached approximately $4 \mathrm{~mm} \times 4 \mathrm{~mm}$ (length $\times$ width), the mice were randomly divided into three groups (control, $40 \mathrm{mg} / \mathrm{kg}$ VES and $80 \mathrm{mg} / \mathrm{kg}$ VES, $\mathrm{n}=8$ ). VES was injected intraperitoneally once every two days for 28 days. After the experiment, nine mice were kept to monitor their survival time.

\section{Statistical analysis}

All experiments were performed at least three times. Data are presented as mean values \pm SD. Statistical differences were evaluated by ANOVA. Values with $\mathrm{P}<0.05$ were considered statistically significant.

\section{Results}

\section{VES induces phagocytosis of HeLa cancer cells by THP-1 macrophages}

After treatment with $10 \mu \mathrm{g} / \mathrm{mL}$ VES for $24 \mathrm{~h}$, the HeLa cancer cells were co-cultured with THP-1 macrophages for 30, 60, 90, $120 \mathrm{~min}$. The phagocytosis of the HeLa cells by macrophages was evaluated using fluorescence microscopy and flow cytometry. Figure 1 shows that exposure to VES greatly increases the degree of THP-1 macrophage-mediated phagocytosis of these tumour cells. This effect was found to be maximal when the tumour cells were co-cultured with THP-1 macrophages for $60 \mathrm{~min}$. The phagocytic rate increased from $8.1 \%$ to $26.5 \%$. In addition, the florescent images clearly confirmed that THP-1 macrophages had phagocytised the HeLa cancer cells.

\section{Effect of VES on CD47 and calreticulin expression of HeLa cancer cells}

CD47 and calreticulin levels were analysed using qRT-PCR and flow cytometry to examine whether phagocytosis of the human cervical cancer cells by THP-1 macrophages is mediated by phagocytic molecules. Our data showed that VES treatment produced down-regulation of the mRNA levels of CD47 in HeLa, CaSki and SiHa cells. Exposure of the HeLa cells to VES resulted in the up-regulation of the 
CRT mRNA. The concentration of surface CD47 protein decreased in the VES-treated HeLa, CaSki and $\mathrm{SiHa}$ cells. But CRT protein was not expressed on the surface of Hela cells both with and without the treatment of VES (Figs. 2A, 2B and 2C).

\section{A}

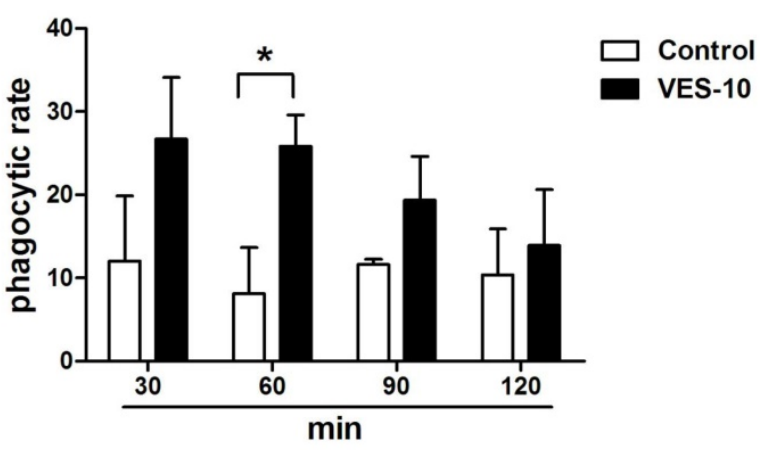

B

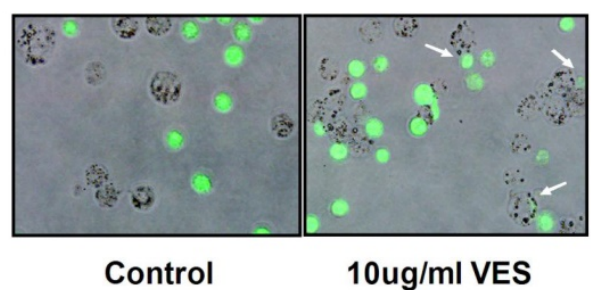

Figure 1. VES induces phagocytosis of HeLa cancer cells by THP-1 macrophages. (A) After treatment of $10 \mu \mathrm{g} / \mathrm{mL}$ VES for $24 \mathrm{~h}$, the HeLa cancer cells were co-cultured with THP-1 macrophages for 30, 60, 90, 120 min. Phagocytosis of the tumour cells by macrophages was evaluated via flow cytometry after the treatment of PE-conjugated anti-CDI lc antibody. Phagocytic rate was the number of phagocytosed cancer cells in 100 THP-1 macrophages.*P $\leq 0.05$ compared with control. (B) Microscope image of THP-1 macrophages that phagocytosed HeLa cancer cells. HeLa cancer cells loaded with CFSE (green fluorescence) were co-cultured with THP-1 macrophages for $60 \mathrm{~min}$. Arrows, individual phagocytosed HeLa cancer cells. The data are representative of at least 3 independent experiments.

\section{miRNAs mediate CD47 expression in VES-treated HeLa cancer cells}

The HeLa cancer cells were treated with 5, 7.5 and $10 \mu \mathrm{g} / \mathrm{mL}$ VES for a time period of $3 \mathrm{~h}$, and, separately, for $6 \mathrm{~h}$. miRNA-155, miRNA-133 and miRNA-326 were analysed by qRT-PCR. Exposure of cells to VES induced miRNA-155, miRNA-133 and miRNA-326. Analysis revealed that miRNA-133 and miRNA-326 increased to the maximum in the cells that had been exposed to $7.5 \mu \mathrm{g} / \mathrm{mL}$ VES. By comparison, miRNA-155 increased to the maximum in the cells exposed to $10 \mu \mathrm{g} / \mathrm{ml}$ VES (Fig. 3A).

The VES-treated HeLa cells were cultured and transfected with the inhibitors of miRNA-155, miRNA-133 and miRNA-326 to assess the miRNAs on CD47 expression. CD47 levels were examined after 24 $\mathrm{h}$ of VES treatment using Western Blotting. Results showed that knockdown of miRNA-155 and miRNA-133 significantly reversed VES-induced decrease in $\mathrm{CD} 47$ protein expression. By contrast, the alteration of CD47 was not reversed by miRNA-326 down-regulation (Fig. 3B).

\section{VES inhibits the growth of HeLa xenografts in nude mice}

The reduction in tumour mass may be taken to be a reliable indicator of strong anti-tumour effects on the basis of accumulating and consistent evidence from a sufficiently large number of different and widely-accepted studies [17, 18]. The anti-tumour effects of VES were evaluated in the HeLa tumour-bearing mice both (I) at a dose of 40 and (II) at $80 \mathrm{mg} / \mathrm{kg}$. The mean tumour volumes in both VES treatments (I) and (II) were significantly lower than those in the control $(\mathrm{P}<0.05$ for both groups, Figs. 4A and $4 \mathrm{~B})$. Correspondingly, the mean tumour weights were lower for the VES groups (I) and (II) $(0.78 \pm 0.04$ and $0.72 \pm 0.03 \mathrm{~g}$ for 40 and $80 \mathrm{mg} / \mathrm{kg}$ VES, respectively) compared with those in the control group $(0.98 \pm 0.12 \mathrm{~g}, \mathrm{P}<0.05$, Table 1$)$. The mean survival time of the control, the VES group (I) and the VES group (II) were $66 \pm 3.6,79.7 \pm 2.08$ and $86 \pm 2.65$ days, respectively. Notably, the VES group(II) showed a substantially higher life extension value than the control $(\mathrm{P}<0.05$, Table 2$)$.

Table 1. Average weights of HeLa xenografts in nude mice from different groups (mean $\pm S E, n=5$ )

\begin{tabular}{lll}
\hline Group & Tumor weight $(\mathrm{g})$ & Rate of tumor inhibition $(\%)$ \\
\hline Control & $0.98 \pm 0.12$ & - \\
$40 \mathrm{mg} / \mathrm{kg}$ VES & $0.78 \pm 0.04^{*}$ & 20.04 \\
$80 \mathrm{mg} / \mathrm{kg}$ VES & $0.72 \pm 0.03^{*}$ & 26.07 \\
\hline Note: ${ }^{*} P<0.05$ compared with the control group.
\end{tabular}

Table 2. The mean survival time of HeLa xenografts in nude mice from different groups (mean $\pm S E, n=3$ )

\begin{tabular}{ll}
\hline Group & Survival time (days) \\
\hline Control & $66 \pm 3.6$ \\
$40 \mathrm{mg} / \mathrm{kg}$ VES & $79.7 \pm 2.08^{*}$ \\
$80 \mathrm{mg} / \mathrm{kg}$ VES & $86 \pm 2.65^{*}$ \\
\hline
\end{tabular}

Note: ${ }^{*} P<0.05$ compared with the control group.

\section{VES reduces CD47 expression in HeLa xenografts of nude mice}

To assess the effect of VES on CD47 in HeLa xenografts of nude mice, we examined CD47 expression by means of qRT-PCR assays and Western Blotting. Our results showed that VES (I) and VES (II) concentrations significantly inhibited CD47 mRNA and protein expression in the tumours of the mice under examination (Fig. 5). 
A
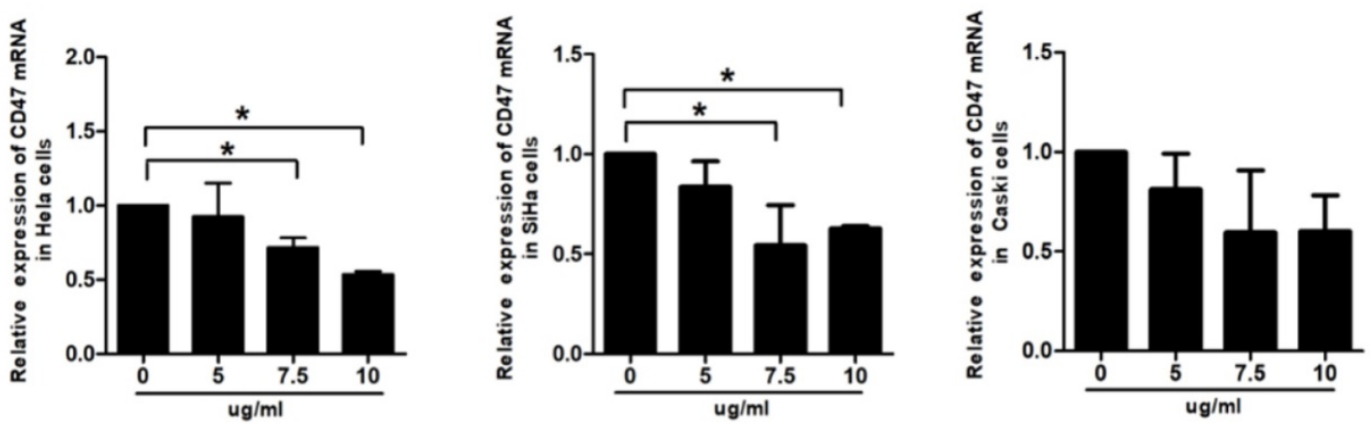

B
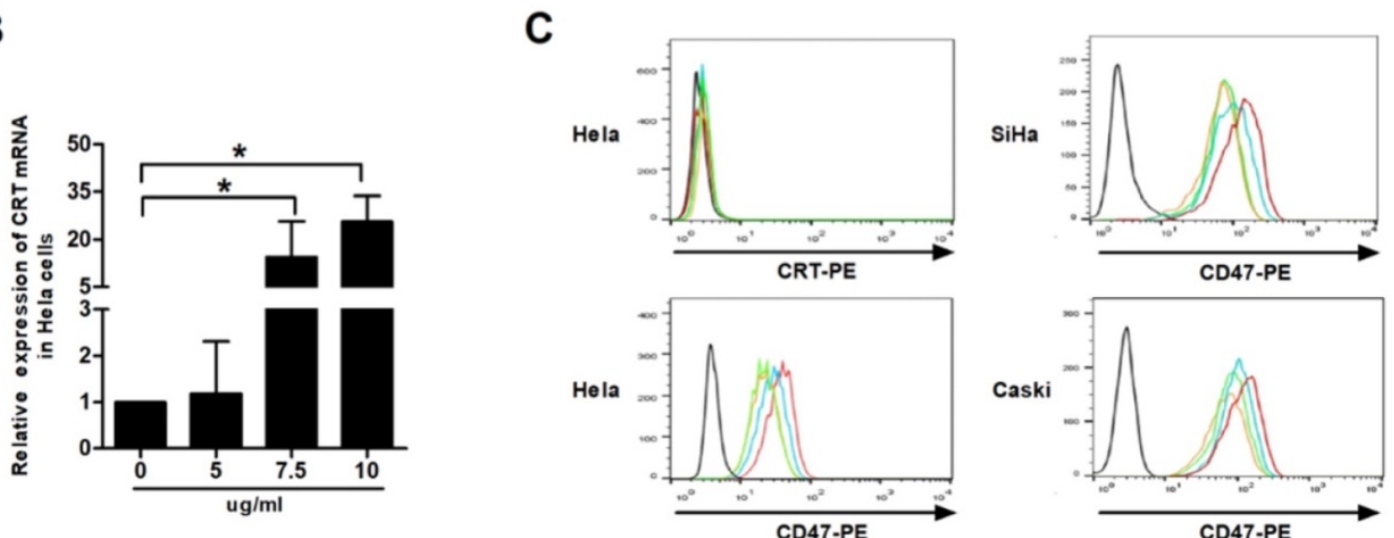

Figure 2. Effect of VES on CD47 and calreticulin expression of human cervical cancer cells. (A) HeLa, CaSki and SiHa cancer cells were treated with 5 , 7.5 and 10 $\mu \mathrm{g} / \mathrm{mL}$ VES for $12 \mathrm{~h}$, and the expression of CD 47 was examined by quantitative real-time PCR. (B) HeLa cancer cells were treated with $5,7.5$ and $10 \mu g / \mathrm{mL}$ VES for $12 \mathrm{~h}$, and the

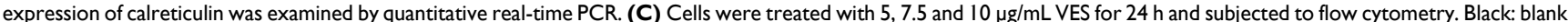
control, red: control group, blue: $5 \mu \mathrm{g} / \mathrm{mL}$ VES group, orange: $7.5 \mu \mathrm{g} / \mathrm{mL}$ VES group, green: $10 \mu \mathrm{g} / \mathrm{mL}$ VES group. The data are representative of at least 3 independent experiments. ${ }^{*} \mathrm{P} \leq 0.05$ compared with control.

A

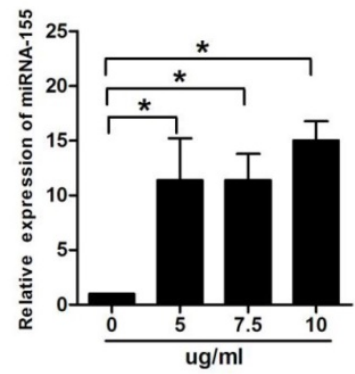

B

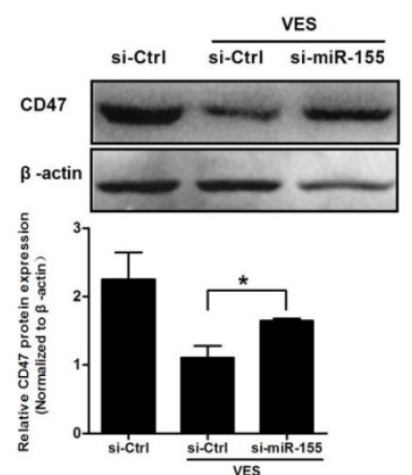

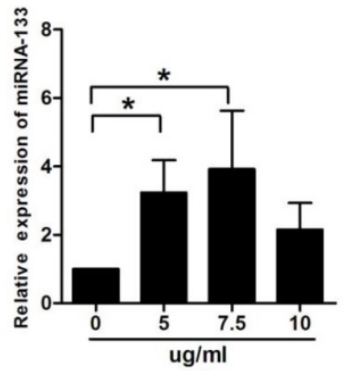
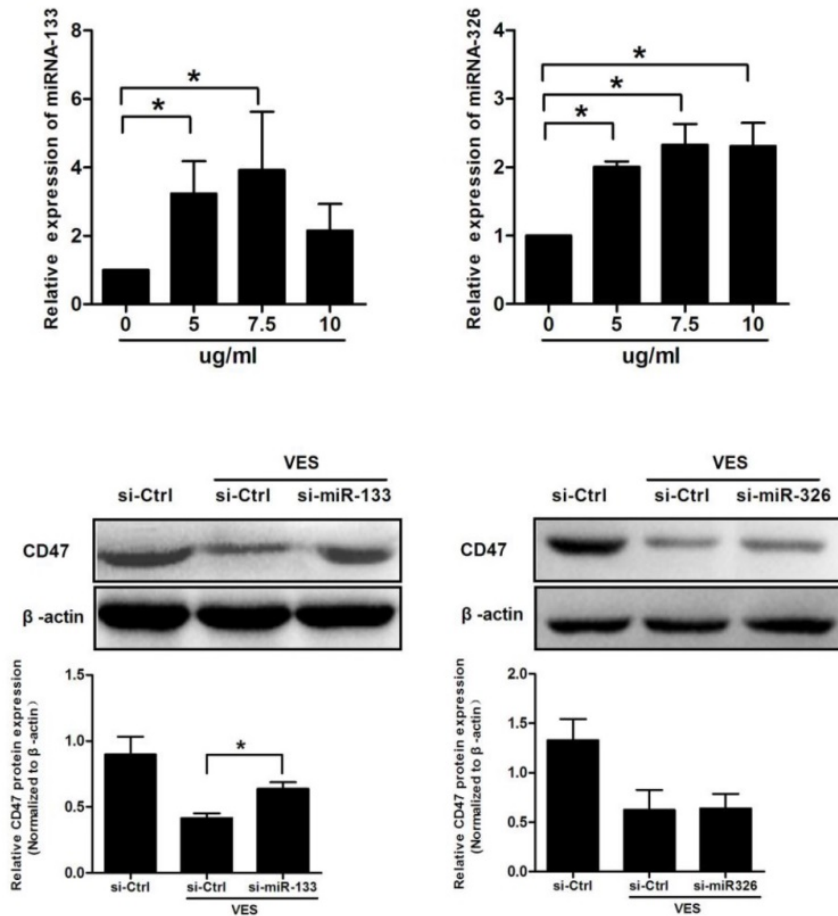

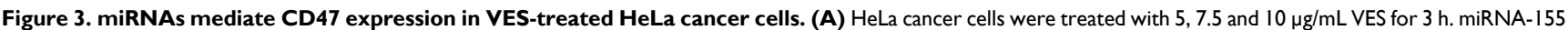
and miRNA-1 33 were examined via quantitative real-time PCR. After the cells were treated with VES for $6 \mathrm{~h}$, miRNA-326 was measured. (B) After $30 \mathrm{~h}$ of transfection with the inhibitors of miRNA-133 and miRNA-326 and exposure of the cells to $7.5 \mu \mathrm{g} / \mathrm{mL}$ VES for $24 \mathrm{~h}, \mathrm{CD} 47$ expression was examined via immunoblotting. After miRNA-155 siRNA-transfected cells were treated with $10 \mu \mathrm{g} / \mathrm{mL}$ VES for $24 \mathrm{~h}, \mathrm{CD} 47$ level was measured. The data are representative of at least 3 independent experiments. *P $\leq 0.05$ compared with control. 


\section{VES alters the expression of inflammatory factors in the spleen of tumour-bearing mice}

To further investigate the effects of VES on inflammatory factors in tumour-bearing mice, we examined TNF- $\alpha$, IL-12, IFN- $\gamma$, IL-2 and IL-10 in the spleen by use of qRT-PCR assays. The pro-inflammatory cytokines (TNF-a, IL-12, IFN- $\gamma$ and IL-2) increased in the spleen of tumour-bearing mice that had been treated with VES, whereas the anti-inflammatory cytokine IL-10 decreased transcriptionally (Fig. 6).

\section{Discussion}

VES, a bio-active molecular compound, has been

A

Control
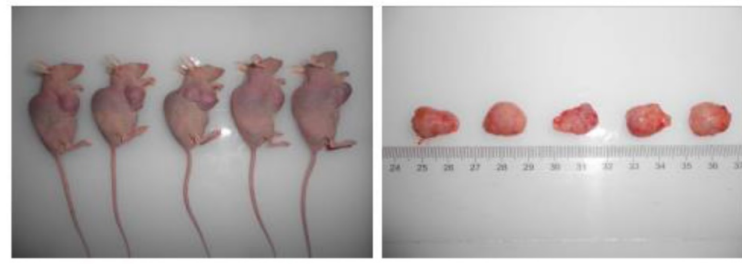

$40 \mathrm{mg} / \mathrm{kg}$ VES group
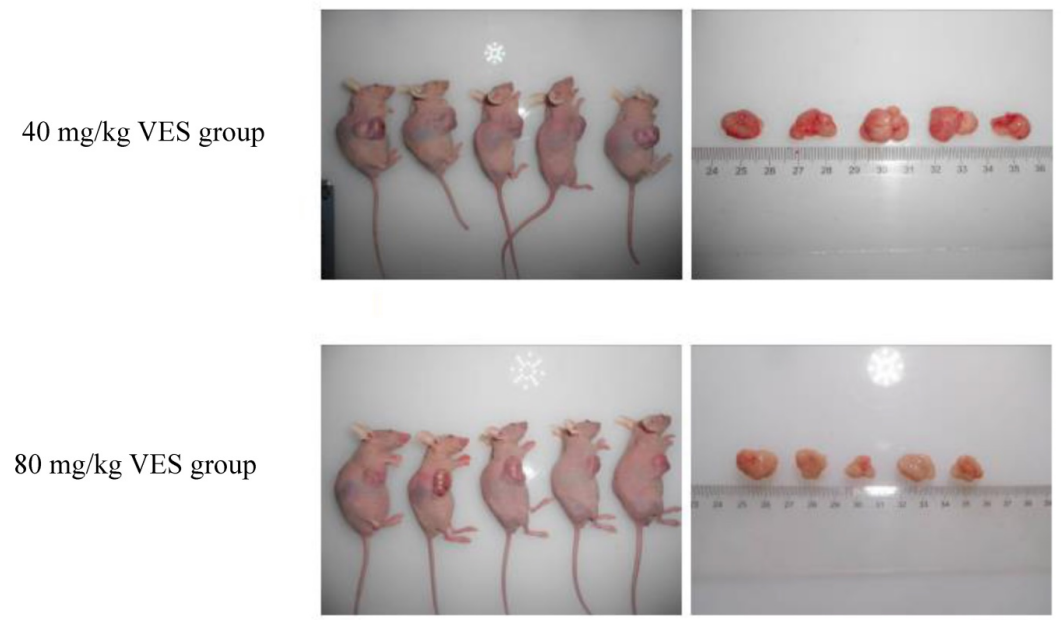

B

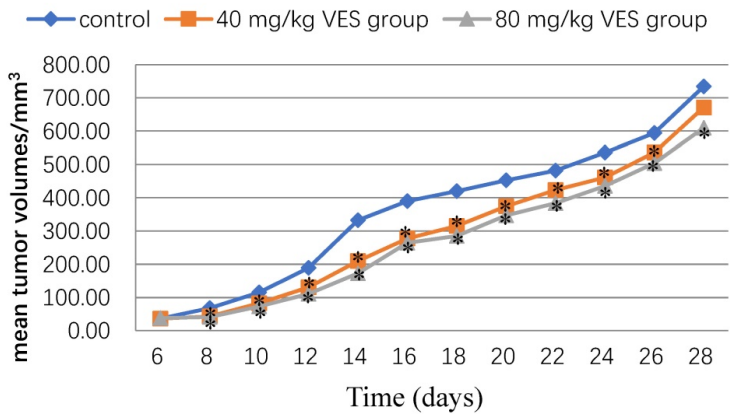

Figure 4. VES inhibits the growth of HeLa xenografts in nude mice. (A) Photographs of tumours from each treatment group excised from tumour-bearing mice. (B) Tumour volume changes after VES treatment on tumour-bearing mice (mean $\pm S D, n=5$ ). $* P \leq 0.05$ compared with control. regarded for some time as a highly suitable chemotherapeutic agent, because of its anti-carcinogenic properties with no toxicity to normal cells or tissues $[19,20]$. VES has been shown to inhibit the tumour growth of xenografted human colon and breast tumour and allografted murine melanoma when administered i.p. [19, 21, 22]. VES also suppresses chemical carcinogen-induced forestomach cancer in animal models [23]. The present study has generated consistent data that convincingly show that intra-abdominal treatment with VES - in VES (I) and (II) concentrations (40 and $80 \mathrm{mg} / \mathrm{kg}$ ) is a useful and effective method for significantly decreasing the weight and volume of tumour mass in HeLa tumour-bearing mice and for prolonging the survival time of the murine specimen.

Therefore: our results, which are consistent with those of previous studies, provide novel-additive, substantial and significant evidence in further support of the excellent anticancer activity of VES in vivo, and its broad anticancer effects to suppress cell growth via a variety of cell fates, including induction of apoptosis, DNA synthesis arrest and cellular differentiation [24-27]. Our previous findings showed that endoplasmic reticulum stress, reactive oxygen species and intracellular TRAIL signalling are involved in VES-induced apoptosis in human gastric cancer cells $[13,14,16$, 28]. Work by the group of Ramanathapuram provided evidence that VES treatment in combination with dendritic cells significantly increases the secretion of IFN-gamma compared with $\mathrm{T}$ cells from control and inhibits tumour growth in mice [29]. VES has also been shown to modulate cell proliferation and cytokine production of murine EL-4 thymic lymphoma [30]. Tomasetti and Neuzil confirmed that INF-gamma production by $\mathrm{CD} 4+$ and CD8+ $\mathrm{T}$ lymphocytes are induced by VES and TRAIL treatment in combination with dendritic cells [31]. In agreement with these studies by other well-regarded research groups, our own previous results also demonstrated that VES up-regulates TRAIL expression in human CD4+ $\mathrm{T}$ cells, and that the combination of human CD4+ T cells and VES induces high anticancer activity of 
VES [16]. Our preliminary data already indicated the possibility that VES may have antitumour effects by regulating the activity of the immune system. Now, with this present study, we are pleased to present new data clearly demonstrating that exposure to VES in 10 $\mu \mathrm{g} / \mathrm{mL}$ concentration can greatly increase THP-1 macrophage-mediated phagocytosis of the HeLa

\section{A}

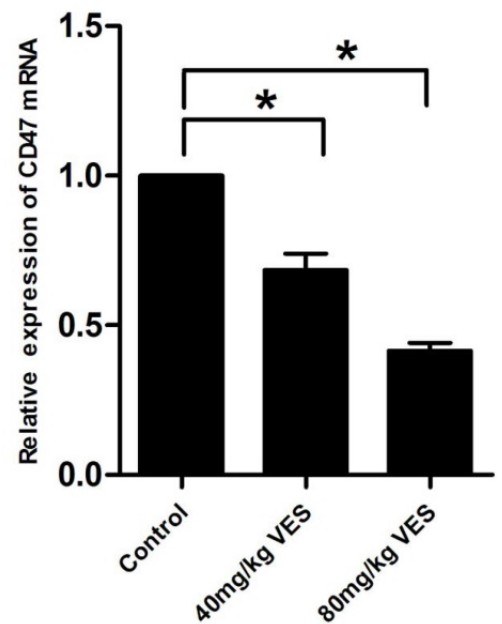

cancer cells. Our present work substantially contributes to the view that the VES treatment constitutes a suitable method by substantially and therewith effectively increasing the phagocytosis rate of the HeLa cancer cells from $8.1 \%$ to $26.5 \%$ as shown by our experiments.

B

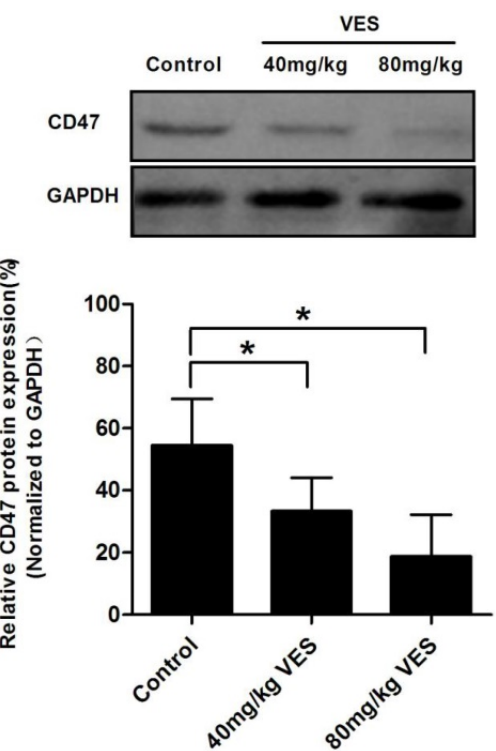

Figure 5. VES reduces CD47 expression in HeLa xenografts of nude mice. After the model of tumour-bearing mice was established, 40 and $80 \mathrm{mg} / \mathrm{kg}$ VES were injected intraperitoneally once every two days for 28 days. (A) CD47 mRNA in tumour excised from nude mice was detected by quantitative real-time PCR assays. $\beta$-Actin was used as a loading control. (B) CD47 protein in tumour excised from nude mice was detected by Western blotting. GAPDH was used as a loading control. Data are representative of at least three independent experiments. *P $\leq 0.05$ compared with control. The data are representative of at least 3 independent experiments.
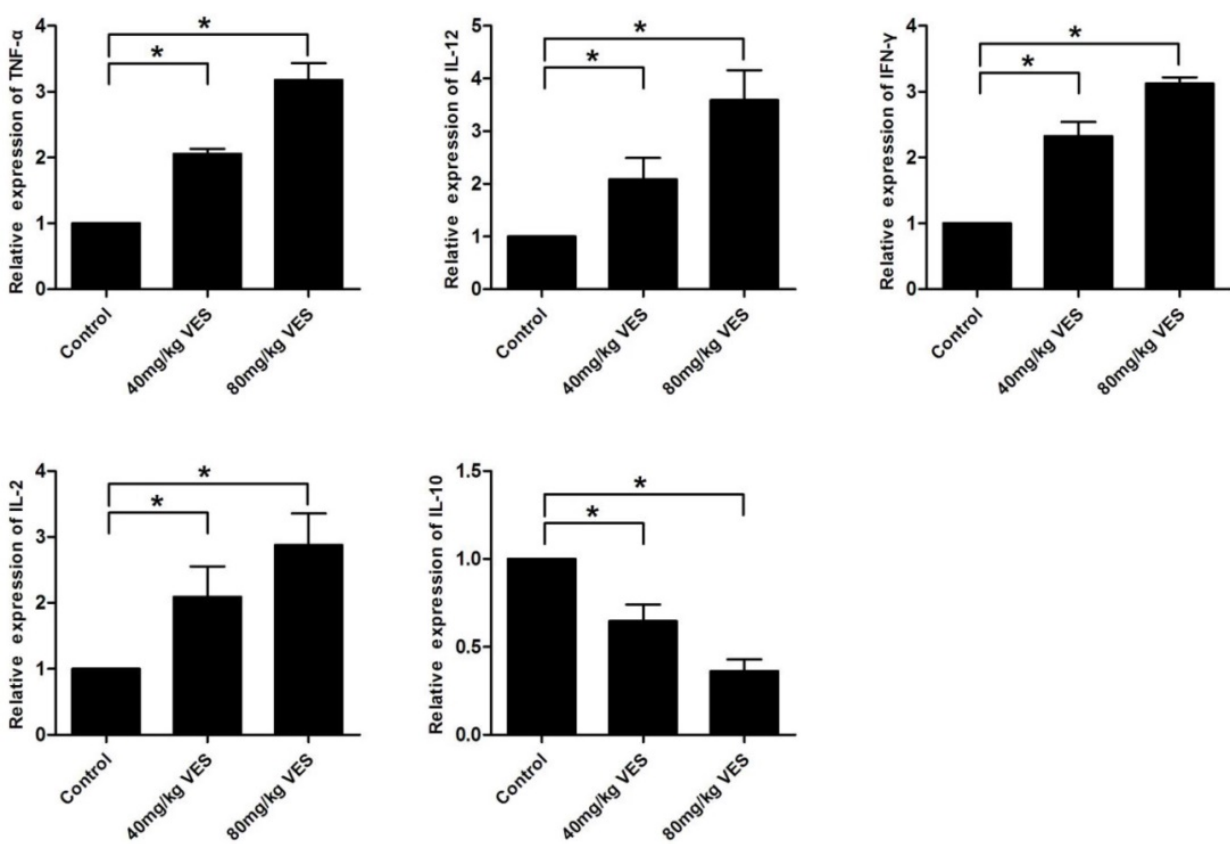

Figure 6. VES alters the expression of inflammatory factors in the spleen of tumour-bearing mice. After the model of tumour-bearing mice was established, 40 and $80 \mathrm{mg} / \mathrm{kg}$ VES were injected intraperitoneally once every two days for 28 days. Inflammatory factors TNF-a, IL-12, IFN-y, IL-2 and IL-10 in the spleen of tumour-bearing mice were examined by quantitative real-time PCR assays. $\beta$-Actin was used as a loading control. Data are representative of at least three independent experiments. $* P \leq 0.05$ compared with control. The data are representative of at least 3 independent experiments. 
In recent years, escape from immune surveillance is increasingly considered as a landmark event in cancer biology [32]. The regulation of the anti-phagocytic signal CD47 is crucially important to surveillance against cancer cells [33]. CD47 is a widely expressed transmembrane glycoprotein, which is also known as integrin-associated protein [34]. CD47 is highly expressed in several human cancer types, such as non-Hodgkin's lymphomas, myeloid leukaemia, glioblastoma, leiomyosarcoma [35-38]. High levels of CD47 expression have been found also in carcinomas, including breast, ovarian, bladder, colon, hepatocellular and cervical cancers [38, 39]. CD47 performs its anti-phagocytic role by binding SIRPa on phagocytic cells, such as macrophages and dendritic cells, which makes SIRPa tyrosine phosphorylation, and by emitting inhibitory regulatory signals [8]. The mechanism by which CD47 inhibits phagocytosis of tumour cells is well-understood thanks to robust and conclusive experimental and analytical work as reported in previous studies [6, 34]. The CD47 blockade not only leads to macrophage surveillance of the innate immune system but also stimulates the adaptive immune system T-cell cytotoxicity [40]. In addition, CD47 is involved in tumour progression, metastasis and outcome [41, 42]. Therefore, CD47 should be regarded as a high-profile potential therapeutic target in cancer. In the present study, we have demonstrated that CD47 expression in the different human cervical cancer cells in vitro and in the HeLa xenografts of nude mice can be transcriptionally and translationally inhibited in response to VES. Therefore, it may be concluded that the CD47/SIRPa axis plays a very important functional role in the VES-induced anti-tumour activity on human cervical cancer cells.

Calreticulin, is an intracellular calcium-binding protein which is also known as an 'eat-me' signal. Calreticulin has been shown to be involved in anticancer immune response [43]. CRT, which is predominantly localised in the lumen of the endoplasmic reticulum, can also translocate to cancer cell surfaces from where CRT provides the signal that is recognised by dendritic cells or other antigen-presenting cells [44]. Binding of cell surface calreticulin to its macrophage receptor, a low-density lipoprotein-related protein, results in the phagocytosis of the target cell [43, 44]. Our study has discovered that exposure of the HeLa cancer cells to VES induces CRT mRNA in the HeLa cells, whilst CRT protein is not expressed on the surface of Hela cells both with and without the treatment of VES. Hence, it can be reasoned that the CRT signal may not participate in the anticancer response of VES.

Previous research has shown that secretion of a large number of inflammatory cytokines is observed in tumour immune response and macrophage activation [45]. Lian and co-workers reported that efficient silencing of CD47 and programmed death-ligand 1 increase the release of various cytokines, including IL- 6 and IFN- $\gamma$, in vitro and in vivo [46]. Vermeer and associates published a study on the effects of radiation-induced loss of cell surface CD47, namely an increase in phagocytosis of these cells by dendritic cells and also induction of IFN- $\gamma$ and granzyme production from lymphocytes [47]. Navarathna's group examined CD47 $/$ mice and found that the serum inflammatory cytokines TNF- $\alpha$, IL-6 and IL-10 were significantly elevated but IL-17 was decreased [48]. In addition, Demeure and co-workers discovered that CD47 engagement suppresses cytokine production by dendritic cells, including IL-12, TNF-a, GM-CSF and IL-6 [49]. All of these studies provide strong, consistent and converging evidence that numerous cytokines are involved in the immune response mediated by CD47. Our results show that pro-inflammatory cytokines (TNF- $\alpha$, IL-12, IFN- $\gamma$ and IL-2) increase in the spleen of tumour-bearing mice when treated with VES, whereas the anti-inflammatory cytokine IL-10 decreased transcriptionally. Collectively, these data provide strong evidence that VES-induced antitumour activity on human cervical cancer cells is coupled to the CD47-SIRPa pathway.

However, the precise mechanisms by which CD47 expression is regulated remain unclear. Previous studies reported that miRNAs are involved in the regulation of CD47 expression. For example, Junker's group showed that three microRNAs, namely, miRNA-34a, miRNA-155 and miRNA-326, when up-regulated in active multiple sclerosis lesions, target the 3'-untranslated region of CD47 and reduce CD47 in brain resident cells [50]. Suzuki and co-workers have found that CD47 expression in oesophageal squamous cell carcinoma is directly suppressed by the miRNA-133a tumour suppressor [51]. Vasques-Nóvoa and associates discovered that miRNA-155 up-regulation in septic myocardium directly targets CD47 in isolated cardiac microvascular endothelial cells [52]. In agreement with this set of previous studies, the results of our own present study show that exposure of the HeLa cancer cells to VES induces miRNA-155, miRNA-133 and miRNA-326. We have found that, unlike miRNA326 down-regulation, knockdown of miRNA-155 and miRNA-133 significantly reversed VES-induced decrease in CD47 protein expression. On the basis of these important findings, we therefore wish to propose that miRNA-155 and miRNA-133 are likely to 
contribute to VES-induced CD 47 down-regulation in human HeLa cancer cells.

In summary, we are delighted that our present study provides strong and consistent two-fold evidence for the first time:firstly that VES-induced anti-tumour activity on human cervical cancer cells is mediated, at least in part, by the CD47-SIRPa pathway in vivo and in vitro, and secondly that the phagocytosis of tumour cells by macrophages is implicated in this process. We are confident that this study constitutes a valuable and important contribution to advancing the present state of knowledge and that our work will help to further deepen the systematic understanding of the ways in which the CD47-SIRPa pathway plays a critical role in the regulation of anti-tumour activity in VES-exposed cells. We wish to share with the wider research community our view that thorough investigation of the mechanisms underlying VES-induced anticancer efficacy would be a praise-worthy goal of future research. Our own team certainly hopes and plans to contribute to these endeavours in the future.

\section{Acknowledgements}

Conceived and designed the experiments: Xun Qu. Performed the experiments: Xiaoli Huang and Di Jia. Analyzed the data: Jintang Sun and Yu Dou. Contributed reagents/materials/analysis tools: Dan $\mathrm{Ai}$ and Zhaodi Nan. Wrote the paper: Markus Neckenig. This work was supported in part by grants from the National Natural Science Foundation of China (No. 81772879).

\section{Competing Interests}

The authors have declared that no competing interest exists.

\section{References}

1. Kagabu M, Nagasawa $T$, Fukagawa $D$, et al. Immunotherapy for Uterine Cervical Cancer. Healthcare (Basel). 2019; 7:108.

2. Bray F, Ferlay J, Soerjomataram I, et al. Global cancer statistics 2018: GLOBOCAN estimates of incidence and mortality worldwide for 36 cancers in 185 countries. CA Cancer J Clin. 2018; 68:394-424.

3. Locy H, de Mey S, de Mey W, et al. Immunomodulation of the Tumor Microenvironment: Turn Foe into Friend. FRONT IMMUNOL. 2018; 9.2909.

4. Ma L, Zhu M, Gai J, et al. Preclinical development of a novel CD47 nanobody with less toxicity and enhanced anti-cancer therapeutic potential. J Nanobiotechnology. 2020; 18:12.

5. Yang H, Shao R, Huang $H$, et al. Engineering macrophages to phagocytose cancer cells by blocking the CD47/SIRPa axis. Cancer Med. 2019; 8:4245-4253.

6. Schurch CM, Forster S, Bruhl F, et al. The "don't eat me" signal CD47 is a novel diagnostic biomarker and potential therapeutic target for diffuse malignant mesothelioma. ONCOIMMUNOLOGY. 2017; 7:e1373235.

7. Dheilly E, Majocchi S, Moine V, et al. Tumor-Directed Blockade of CD47 with Bispecific Antibodies Induces Adaptive Antitumor Immunity. Antibodies (Basel). 2018; 7:3

8. Soto-Pantoja DR, Kaur S, Roberts DD. CD47 signaling pathways controlling cellular differentiation and responses to stress. Crit Rev Biochem Mol Biol. 2015:50:212-230.

9. Li CW, Lai YJ, Hsu JL, et al. Activation of phagocytosis by immune checkpoint blockade. Front Med. 2018; 12:473-480.

10. Li F, Lv B, Liu Y, et al. Blocking the CD47-SIRPalpha axis by delivery of anti-CD47 antibody induces antitumor effects in glioma and glioma stem cells. ONCOIMMUNOLOGY. 2018; 7:e1391973.
11. Savitskaya MA, Onischenko GE. alpha-Tocopheryl Succinate Affects Malignant Cell Viability, Proliferation, and Differentiation. Biochemistry (Mosc). 2016; 81:806-818.

12. Angulo-Molina A, Reyes-Leyva J, Lopez-Malo A, et al. The role of alpha tocopheryl succinate (alpha-TOS) as a potential anticancer agent. NUTR CANCER. 2014; 66:167-176.

13. Huang X, Zhang Z, Jia L, et al. Endoplasmic reticulum stress contributes to vitamin E succinate-induced apoptosis in human gastric cancer SGC-7901 cells. CANCER LETT. 2010; 296:123-131.

14. Huang $\mathrm{X}$, Li L, Zhang L, et al. Crosstalk between endoplasmic reticulum stress and oxidative stress in apoptosis induced by alpha-tocopheryl succinate in human gastric carcinoma cells. Br J Nutr. 2013; 109:727-735.

15. Zhang $\mathrm{X}$, Peng $\mathrm{X}, \mathrm{Yu} \mathrm{W}$, et al. Alpha-tocopheryl succinate enhances doxorubicin-induced apoptosis in human gastric cancer cells via promotion of doxorubicin influx and suppression of doxorubicin efflux. CANCER LETT. 2011; 307:174-181.

16. Hou L, Zhang H, Xu P, et al. Effect of vitamin E succinate on the expression of the tumor necrosis factor-related apoptosis-inducing ligand (TRAIL) receptor in gastric cancer cells and CD4(+) T cells. MOL BIOSYST. 2015; 11:3119-3128.

17. Losuwannarak N, Maiuthed A, Kitkumthorn N, et al. Gigantol Targets Cancer Stem Cells and Destabilizes Tumors via the Suppression of the PI3K/AKT and JAK/STAT Pathways in Ectopic Lung Cancer Xenografts. Cancers (Basel). 2019; 11:2032.

18. Suzuki N, Nakagawa F, Matsuoka $K$, et al. Effect of a novel oral chemotherapeutic agent containing a combination of trifluridine, tipiracil and the novel triple angiokinase inhibitor nintedanib, on human colorectal cancer xenografts. ONCOL REP. 2016; 36:3123-3130.

19. Tam KW, Ho CT, Tu SH, et al. alpha-Tocopherol succinate enhances pterostilbene anti-tumor activity in human breast cancer cells in vivo and in vitro. Oncotarget. 2018; 9:4593-4606.

20. Neuzil J, Weber T, Gellert N, et al. Selective cancer cell killing by alphatocopheryl succinate. Br J Cancer. 2001; 84:87-89.

21. Malafa MP, Fokum FD, Mowlavi A, et al. Vitamin E inhibits melanoma growth in mice. SURGERY. 2002; 131:85-91.

22. Weber T, Lu M, Andera L, et al. Vitamin E succinate is a potent novel antineoplastic agent with high selectivity and cooperativity with tumor necrosis factor-related apoptosis-inducing ligand (Apo2 ligand) in vivo. CLIN CANCER RES. 2002; 8:863-869.

23. Wu K, Shan YJ, Zhao Y, et al. Inhibitory effects of RRR-alpha-tocopheryl succinate on benzo(a)pyrene $(\mathrm{B}(\mathrm{a}) \mathrm{P})$-induced forestomach carcinogenesis in female mice. World J Gastroenterol. 2001; 7:60-65.

24. You H, Yu W, Munoz-Medellin D, et al. Role of extracellular signal-regulated kinase pathway in RRR-alpha-tocopheryl succinate-induced differentiation of human MDA-MB-435 breast cancer cells. Mol Carcinog. 2002; 33:228-236.

25. $\mathrm{Yu}$ W, Sanders BG, Kline K. RRR-alpha-tocopheryl succinate induction of DNA synthesis arrest of human MDA-MB-435 cells involves TGF-betaindependent activation of p21Waf1/Cip1. NUTR CANCER. 2002; 43:227-236.

26. Neuzil J. Vitamin E succinate and cancer treatment: a vitamin E prototype for selective antitumour activity. Br J Cancer. 2003; 89:1822-1826.

27. Sun $Y$, Zhao Y, Hou L, et al. RRR-alpha-tocopheryl succinate induces apoptosis in human gastric cancer cells via the NF-kappaB signaling pathway. ONCOL REP. 2014; 32:1243-1248.

28. Jia L, Huang XL, Zhao Y, et al. Vitamin E succinate (VES) inhibits cell growth and induces apoptosis by mitochondrial-derived ROS in SGC-7901 cells. Med Sci Monit. 2010; 16:R131-R139.

29. Ramanathapuram LV, Kobie JJ, Bearss D, et al. alpha-Tocopheryl succinate sensitizes established tumors to vaccination with nonmatured dendritic cells. Cancer Immunol Immunother. 2004; 53:580-588.

30. Yu W, Sanders BG, Kline K. Modulation of murine EL-4 thymic lymphoma cell proliferation and cytokine production by vitamin E succinate. NUTR CANCER. 1996; 25:137-149.

31. Tomasetti M, Neuzil J. Vitamin E analogues and immune response in cancer treatment. VITAM HORM. 2007; 76:463-491.

32. Finn OJ. A Believer's Overview of Cancer Immunosurveillance and Immunotherapy. J IMMUNOL. 2018; 200:385-391.

33. Feng M, Chen JY, Weissman-Tsukamoto R, et al. Macrophages eat cancer cells using their own calreticulin as a guide: roles of TLR and Btk. Proc Natl Acad Sci U S A. 2015; 112:2145-2150.

34. Huang Y, Ma Y, Gao P, et al. Targeting CD47: the achievements and concerns of current studies on cancer immunotherapy. J THORAC DIS. 2017; 9:E168-E174.

35. Chao MP, Alizadeh AA, Tang C, et al. Anti-CD47 antibody synergizes with rituximab to promote phagocytosis and eradicate non-Hodgkin lymphoma. CELL. 2010; 142:699-713.

36. Edris B, Weiskopf K, Volkmer AK, et al. Antibody therapy targeting the CD47 protein is effective in a model of aggressive metastatic leiomyosarcoma. Proc Natl Acad Sci U S A. 2012; 109:6656-6661.

37. Chao MP, Alizadeh AA, Tang C, et al. Therapeutic antibody targeting of CD47 eliminates human acute lymphoblastic leukemia. CANCER RES. 2011; 71:1374-1384.

38. Willingham SB, Volkmer JP, Gentles AJ, et al. The CD47-signal regulatory protein alpha (SIRPa) interaction is a therapeutic target for human solid tumors. Proc Natl Acad Sci U S A. 2012; 109:6662-6667. 
39. Liu F, Dai M, Xu Q, et al. SRSF10-mediated IL1RAP alternative splicing regulates cervical cancer oncogenesis via mIL1RAP-NF-kappaB-CD47 axis. ONCOGENE. 2018; 37:2394-2409.

40. Tseng D, Volkmer JP, Willingham SB, et al. Anti-CD47 antibody-mediated phagocytosis of cancer by macrophages primes an effective antitumor T-cell response. Proc Natl Acad Sci U S A. 2013; 110:11103-11108.

41. $\mathrm{Xu} \mathrm{JF}$, Pan $\mathrm{XH}$, Zhang SJ, et al. CD47 blockade inhibits tumor progression human osteosarcoma in xenograft models. Oncotarget. 2015; 6:23662-23670.

42. Zhao H, Wang J, Kong X, et al. CD47 Promotes Tumor Invasion and Metastasis in Non-small Cell Lung Cancer. Sci Rep. 2016; 6:29719.

43. Wang J, Gao ZP, Qin S, et al. Calreticulin is an effective immunologic adjuvant to tumor-associated antigens. EXP THER MED. 2017; 14:3399-3406.

44. Schcolnik-Cabrera A, Oldak B, Juarez M, et al. Calreticulin in phagocytosis and cancer: opposite roles in immune response outcomes. APOPTOSIS. 2019; 24:245-255.

45. de Almeida AC, Barbosa SM, de Lourdes RBM, et al. IFN-beta, IFN-gamma, and TNF-alpha decrease erythrophagocytosis by human monocytes independent of SIRP-alpha or SHP-1 expression. Immunopharmacol Immunotoxicol. 2012; 34:1054-1059.

46. Lian S, Xie R, Ye Y, et al. Simultaneous blocking of CD47 and PD-L1 increases innate and adaptive cancer immune responses and cytokine release. EBIOMEDICINE. 2019; 42:281-295.

47. Vermeer DW, Spanos WC, Vermeer PD, et al. Radiation-induced loss of cell surface CD47 enhances immune-mediated clearance of human papillomavirus-positive cancer. INT J CANCER. 2013; 133:120-129.

48. Navarathna DH, Stein EV, Lessey-Morillon EC, et al. CD47 Promotes Protective Innate and Adaptive Immunity in a Mouse Model of Disseminated Candidiasis. PLOS ONE. 2015; 10:e128220.

49. Demeure CE, Tanaka H, Mateo V, et al. CD47 engagement inhibits cytokine production and maturation of human dendritic cells. J IMMUNOL. 2000; 164:2193-2199.

50. Junker A, Krumbholz M, Eisele S, et al. MicroRNA profiling of multiple sclerosis lesions identifies modulators of the regulatory protein CD47. BRAIN. 2009; 132:3342-3352.

51. Suzuki S, Yokobori T, Tanaka N, et al. CD47 expression regulated by the miR-133a tumor suppressor is a novel prognostic marker in esophageal squamous cell carcinoma. ONCOL REP. 2012; 28:465-472.

52. Vasques-Novoa F, Laundos TL, Cerqueira RJ, et al. MicroRNA-155 Amplifies Nitric Oxide/cGMP Signaling and Impairs Vascular Angiotensin II Reactivity in Septic Shock. CRIT CARE MED. 2018; 46:e945-e954. 